\title{
Assessing the performance of the evacuated tube solar collector using smart curtain through (PSO based PID) controller and Nano fluids
}

\author{
Hosham S.Anead (D) a, Khalid F. Sultan ${ }^{\text {b }}$, Sura Abdul Jabbar ${ }^{{ }^{*}}$, \\ ${ }^{a}$ Department of Electromechanical Engineering, University of Technology, Baghdad, Iraq, \\ 50043@uotechnology.edu.iq. \\ ${ }^{\mathrm{b}}$ Department of Electromechanical Engineering, University of Technology, Baghdad, Iraq, \\ 50084@uotechnology.edu.iq \\ ${ }^{c}$ Department of Electromechanical Engineering, University of Technology, Baghdad, Iraq, \\ 50111@student.uotechnology.edu.iq.
}

*Corresponding author.

Submitted: 03/05/2020

Accepted: 24/06/2020

Published: 25/01/2021

K E Y W O R D S

Evacuated Tube Solar, PSO- PID, control, temperatures.

\begin{abstract}
A B S T R A C T
This research revealed control on Nano fluid temperature in the evacuated tube solar collector system, where Nano fluids used in ETSC as working fluid to increase heating system thermal efficiency. Smart curtain was used to shadow the evacuated tube solar collector and to control the temperature of the Nano fluid in heating or cooling condition which is moved by the stepper motor which is programmed to move through the Arduino board using an artificial intelligence method such as (PSO based PID) controller method. Where the curtain's main idea is to control the polarization of the sun's radiation, the work of the curtain refers to the parameters: the first parameter is the Nano fluid temperature and the second is sun radiation falling on the collector, and one output parameter is defined by (distance parameter).
\end{abstract}

\footnotetext{
How to cite this article: H. S. Anead, K. F., Sultan , and S. A. Ahmed, " Assessing the performance of the evacuated tube solar collector using smart curtain through (PSO based PID) controller and Nano fluids ," Engineering and Technology Journal, Vol. 39, Part A, No. 01, pp. 137-152, 2021.

DOI: https://doi.org/10.30684/etj.v39i1A.1701

This is an open access article under the CC BY 4.0 license http://creativecommons.org/licenses/by/4.0
}

\section{INTRODUCTION}

Solar energy is a significant source of renewable energy for use with various techniques; solar collectors capture their energy from sun. To make this development a major source for the future, research and development must address a number of issues, such as capacity, space and the environment [1].Solar power has become more attractive because it is safe, and available without any restrictions. Solar collectors are the latest systems to capture heat from solar energy that can be used in most buildings, such as air conditioning, water heating, swimming pool heating, and so on [2].Nevertheless, solar power as an everlasting and ubiquitous source of power is constantly changing, as main drawback between time of sunlight and use, therefore, accumulation and 
processing of solar power during the time of radiation is important for duration of use [3].Solar collectors are a significant component of any cycle of solar power consumption, these function is to capture the incoming solar radiation and convert it into heat, transition of energy to a liquid flowing through the collector (generally air, liquid or a special thermal energy fluid) [4]. There are a number of techniques to absorb solar radiation, but the evacuated tube method has a particular interest to the researchers because ETSC have much greater efficiencies than typical FPC, especially at low temperatures and insulation presence [5]. From another side Nano fluids are the most attractive means to boost heat transfer system efficiency. Since they have high thermal conductivity, many forms of nanoparticles have been used. They are formed by adding metal and metal oxides Nano-particles with a diameter below $100 \mathrm{~nm}$ to the base fluid. For solar collectors, renewable energy makes special use of these Nano fluids, evacuated solar collector pipe is one of the solar collectors are widely used in thermal transfer applications [6]. The PID controller is still the most common type of controller used in industry in this new era of modern control applications; the basic operation of PID control consists of a proportional error signal augmented by an integral derivative and error signal [7]. proposed PID tuning approach in this paper is to use the Particle Swarm Optimization (PSO) algorithms, Instead of other algorithms in the evolutionary algorithm (EA) family, PSO algorithm is chosen for PID optimization processes because the PSO has only three steps in the algorithm, therefore PSO is more viable for implementing on low-cost real-time hardware due to the low requirement of memory space for data processing [8]: Kamble D.P.1 et. al. (2014). [9] Studied the Nano fluid's behavior to boost a circular heat pipe's thermal performance. The experiment, made of copper tubing and use hybrid Nano fluid $(\mathrm{Al} 2 \mathrm{O} 3+\mathrm{CuO})$ with a water base as working fluids, it investigates the heat pipe thermal dissipation under various working conditions. Total thermal performance was predicted for distilled water and water based on Nano fluid. Study discusses the impact of the working fluids ' charged volume ratio, the impact of the filling volume ratio and the volume of nanoparticles in the base fluid on thermal resistance are also investigated. In comparison to pure water, the thermal efficiency of the heat pipe increases with the growing $(\mathrm{Al} 2 \mathrm{O} 3+\mathrm{CuO})$ water dependent Nano fluid. Tiwari et al. (2013) [10] Examined the impact of the theoretical use of $\mathrm{Al}_{2} \mathrm{O}_{3}$ Nano fluid as an absorbent medium in a flat-plate solar collector. They also studied the effect on the collector's efficiency, mass flow rate and particle volume fraction. Their results revealed that using the optimal particle volume fraction of $1.5 \%$ of Al2O3 Nano fluid increases the solar collector's thermal efficiency by $31.64 \%$ compared to water as working fluid. H. Aygun1, H. Demire (2011)[11]:Applied ( FLC, PSO-PID), FLC (fuzzy logic controller ) which are new controllers, and classic PID controllers are used to control and compare bed temperatures in rotating fluidized bed boilers, , bed temperature is a significant parameter in a fluidized bed boiler circulating. Since burning efficiency increases as the bed temperature rises and the bed temperature influences negative emissions. The simulation results showed that PSO-PID controller settling time is lower compared to other controllers. PSO-PID reduces overshoot like FLC, but overshoots are the highest in the classical PID system. There is no over-shooting in FLC. Bouarroudj N. et al. (2014) [12]: The PSO method has been used to achieve the optimum angle of inclination of the PV / $\mathrm{T}$ collector to resolve the large datasets necessary to analyze the quality of the system, which is costly and time consuming. Geographical information topography parameters (altitude and longitude) were use as input variable for measurement of solar radiation, whereas the tilt angle of the Photovoltaic thermal hybrid solar collector (PVT) collector was regarded to be the key variable to be adapted to maximize the output of the PVT. Computation results have been shown that the tilting angle has to be modified during the year in order to accomplish maximum efficiency in the $10^{\circ}-60^{\circ}$ range. Obtained solar radiation improved by $(10.06-58.34)$ $\mathrm{W} / \mathrm{m} 2$ when an optimization angle of tilt has been used.

The main objective of this research is to control the temperature of the Nano fluids by shading the solar collector using an electronic curtain which is programmed to move through the Arduino board using (PSO based PID) controller method and to increase the efficiency of solar collector, the curtain movement is adopted to shade the solar collector according to the temperature of the Nano fluids passing through the tubes. The (PSO - PID) also used for forecasting the thermal parameters of evacuated tube solar collector. 


\section{PARTICles SWARMS OPTIMIZATION (PSO)}

This is one of popular algorithms, inspired from nature, and accredited by Eberhart, Kennedy, and Shi. Where PSO is simulating birds and fish schooling's social behavior, which shapes a community of particles that is randomly distributed. Figure 1 shows the structure of particle swarm. This algorithm will boost the solutions based on quality assessment (i.e. fitness function). The improvement is made with the movement of the particles around the search space; this motion was made with several simple mathematical expressions. Such expressions model the interaction between particles, suggesting the motion for each of the particles in the direction of their optimum experienced location and also the best position for the swarm. That particle set its velocity in a dynamic manner, based on its experiences and the experiences of the other particle [13].PSO is based on a simple idea, easy to implement and computationally efficient. This functions by holding in the search space many candidate solutions. Through solution is viewed as a particle that moves through the search space [14].
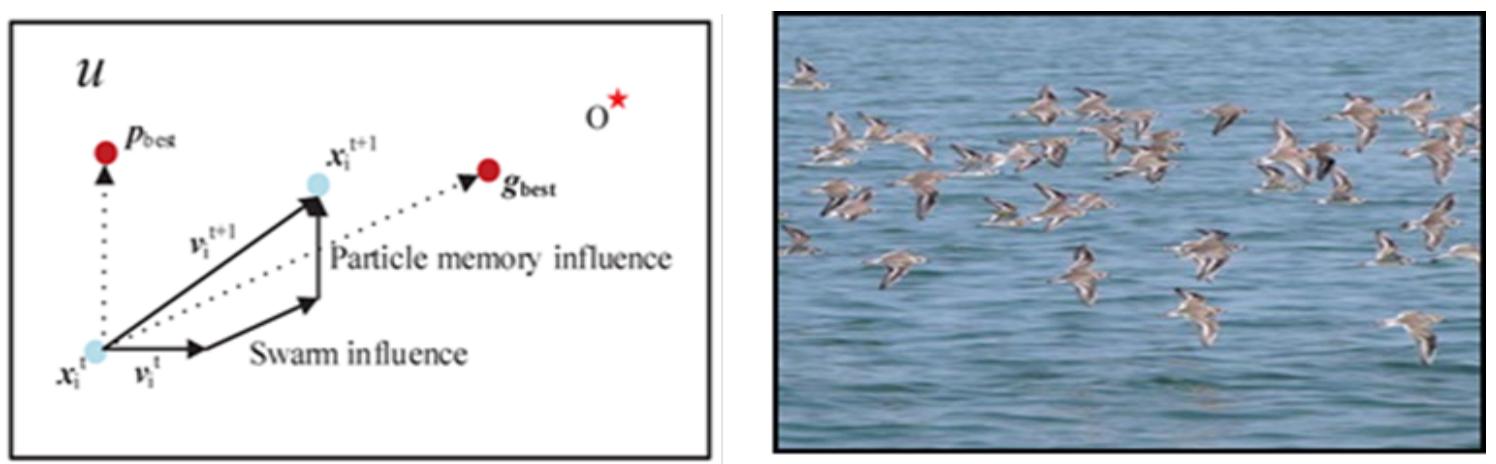

Figure 1: show the structure of particles swarm optimization

\section{Algorithm of Particle Swarm Optimization:}

PSO searches through the particulate Swarm updating from iteration to iteration. The particle moves towards its previously best $\left(\mathrm{p}_{\text {best }}\right)$ position and the global best $\left(\mathrm{g}_{\text {best }}\right)$ position in the swarm to reach the optimal solution, the position in the particles is shown in Eq. (1).

$X i=\left(\begin{array}{lll}X i_{1} & X i_{2} & X i_{3}\end{array}\right), \quad i=1,2,3 \ldots \ldots M$

The speed of the particle is showed in Eq. (2).

$V i=\left(V i_{1} V i_{2} V i_{3}\right), \quad i=1,2,3 \ldots \ldots . M$

Each particle's best position is called the best local position and the best position in the swarm is called the best global position for each parameter. In Eq. (3) and Eq. (4) they are shown

$P i=\left(P i_{1} P i_{2} P i_{3}\right), \quad i=1,2,3 \ldots . M$
$g i=\left(g i_{1} g i_{2} g i_{3}\right), \quad i=1,2,3 \ldots . M$

Speeds of particles are weighted with different random terms

For reaching to the best position. The speed and particle of each

Particle are updated in Eq. (5) and Eq. (6).

$v_{i D}^{t+1}=k\left[v_{i D}^{t}+c_{1} r_{1}\left(p_{i d}^{t}-x_{i D}^{t}\right)+c_{2} r_{2}\left(g_{i}^{t}-x_{i D}^{t}\right)\right]$

$x_{i D}^{t+1}=x_{i D}^{t}+v_{i D}^{t+1}$

Here, the first term at that moment is particle velocity. The second and third terms are particle and swarm observations. $\mathrm{C}_{1}$ and $\mathrm{C}_{2}$ Care positive constant parameters called "acceleration coefficients". $\mathrm{r}_{1}$ and $r_{2}$ are uniformly distributed random variables within range of $[0,1], t$ is the number of the iteration, $\mathrm{K}$ factor used to quarantine optimization convergence performance is shown in Eq. (7).

$k=\frac{2}{\mid 2-\varphi-\sqrt{\varphi^{2}-4 \varphi \mid}} \varphi=c_{1}+c_{2}>4$ 
The position and velocity of the particles must be limited to avoid particles departing from the quest space. Speed value is restricted by the defined peak particle location value and better optimal results are obtained when the particle limits are chosen as more acceptable. In Eq. (8) and Eq. (9), these limits are shown:

$\begin{array}{ll}v^{\max }=k \cdot x^{\max } & 0.1 \leq k \leq 0.5 \\ v^{\min }=-v^{\max } & \end{array}$

If $v^{k+1}$ is bigger than $\mathrm{v}^{\max }, \mathrm{v}^{\mathrm{k}+1}$ will be taken equl to $\mathrm{v}^{\max }$ and iff $\mathrm{v}^{\mathrm{k}+1}$ is

smaller than $\mathrm{v}^{\mathrm{min},} \mathrm{x}^{\mathrm{k}+1}$ will be taken equall to $\mathrm{v}^{\mathrm{min}}$

Also if $\mathrm{x}^{\mathrm{k}+1}$ is bigger than $\mathrm{x}^{\max }, \mathrm{x}^{\mathrm{k}+1}$ is bigger than $\mathrm{x}^{\max }, \mathrm{x}^{\mathrm{k}+1}$ will be taken equall

$\mathrm{x}^{\max }$ And if $\mathrm{x}^{\mathrm{k}+1}$ is smaller than $\mathrm{x}^{\mathrm{min}}, \mathrm{x}^{\mathrm{k}+1}$ will be taken equall to $\mathrm{x}^{\mathrm{min}}$

Here k shows iteration number. PSO starts with a random solution and optimal result is found with updates [15]. 


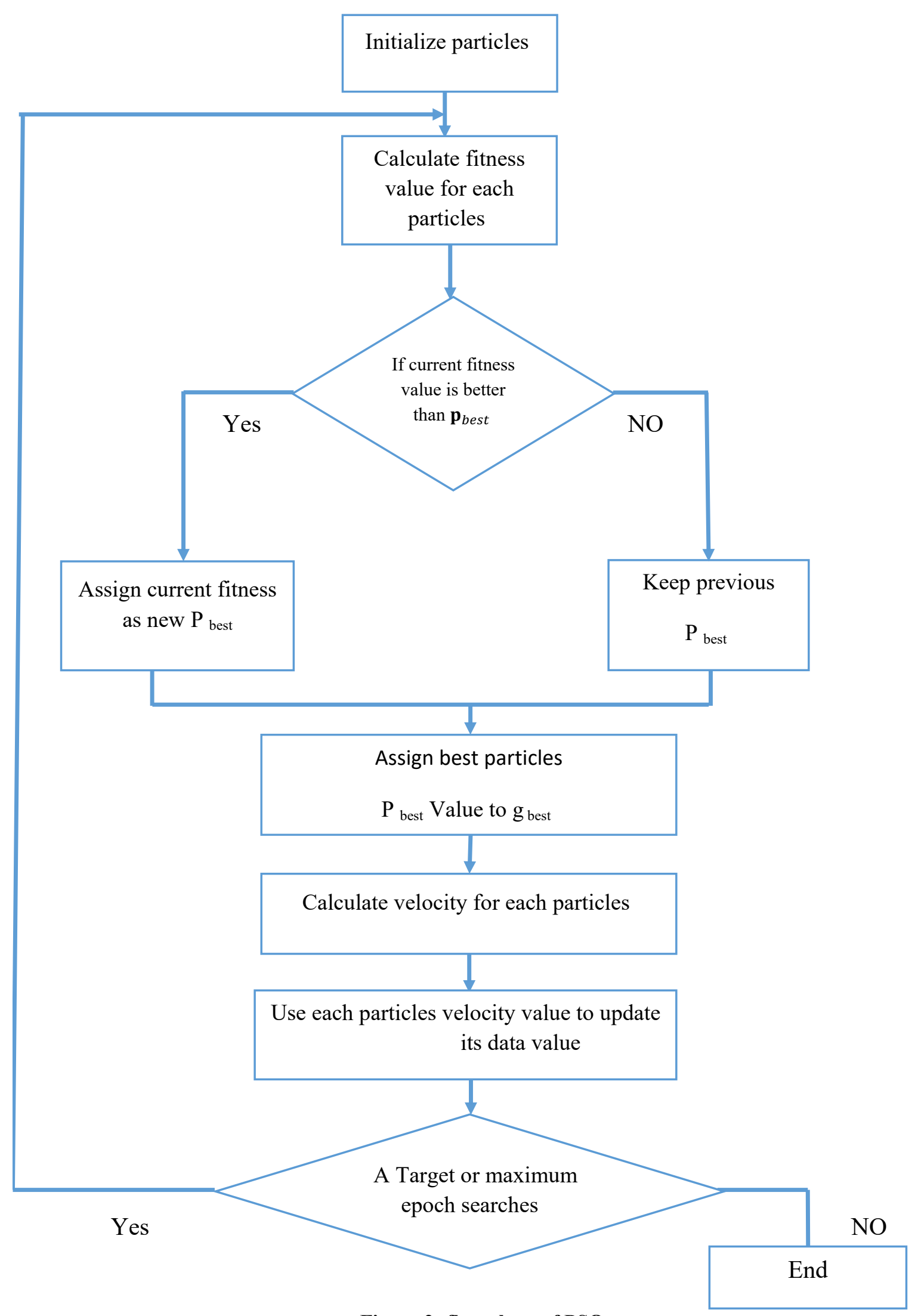

Figure 2: flow chart of PSO 


\section{PSO BASED PID CONTROLLER DESIGN}

The PSO is global search method used to tune the PID controller gain automatically, So that there's minimal transient tracking error. In this new era of modern control systems, PID is the most common type of controller used in industry. Due to its simplicity and robustness, the (Proportional - Integral - Derivative) controller, Designed for various control purposes The PID Control Act can be written as follows:

$$
u(t)=k_{p} e(t)+k_{i} \int e(t) d t+k_{d} \frac{d e(t)}{d t}
$$

Where, $\mathrm{u}(\mathrm{t})=$ input, $\mathrm{e}(\mathrm{t})=$ error,

$\mathrm{Kp}=$ proportional gain, $\mathrm{Ki}=$ integral gain and $\mathrm{Kd}=$ derivative gain

In classical PID controller overshoot are biggest, the PSO based PID controller are used to increase response time as well as reduce or remove the steady state errors [16]. PSO based PID Controller method more flexible and provided a better transient and stable state response than a classical PID controller [17].

\section{EVACUATED TUBE SOLAR COLLECTOR (ETSC)}

Evacuated tube solar collector consists of 10 single ended evacuated tube. Each tube was concentric tubes that annular vacuum space between them prevents of convection inside the glasses tube and heat transfer conduction. The Nano fluid circulates naturally between each tube and horizontal tank, the inner tank is made of stainless steel material, the outer shell is made of galvanized plate and it is insulated using foam. The collector retains heat for 72 hours, manufactured by company of electronic (GeTX) shown in Fig.3 and Table I show the Solar Collector Specification. in this research using two types of Nano fluids such as copper with particle size of $(30 \mathrm{~nm})$ and zirconium oxide $\left(\mathrm{ZrO}_{2}\right)$ with particle size of $(50 \mathrm{~nm})$ and distilled water (DW) as working fluids, Table II show the Nano fluids properties.

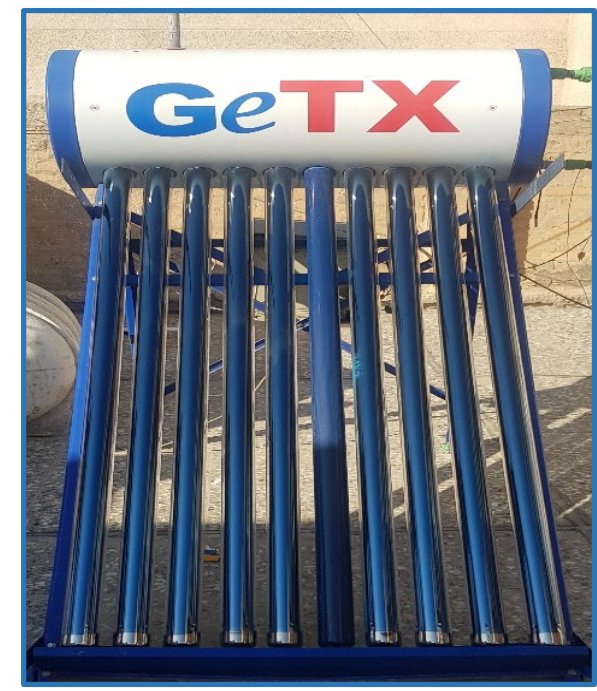

Figure 3: evacuated tube solar collector (ETSC)

Table I: the specification of evacuated tube solar collector

\begin{tabular}{cccc}
\hline \multicolumn{4}{c}{ Solar Collector Specification } \\
\hline Out tank material & White color steel & Capacity & $100 \mathrm{~L}$ \\
\hline Vacuum tube & $47 \mathrm{~mm} \times 1.5$ m series glass tube & Insulation & $\begin{array}{c}\text { High density } \\
\text { pressure }\end{array}$ \\
\hline Frame material & 40 degree galvanized steel & Series No & $0811 \mathrm{JS}$ \\
\hline Inner tank & SUS 3042b food grade & Manufacture date & Feb .13 ${ }^{\text {th }} .2019$ \\
material & $0.41 \mathrm{~mm}$ & &
\end{tabular}


Table II: the properties of Nano fluids

\begin{tabular}{ccccccc}
\hline Base fluid & $\operatorname{Pr}$ & $\begin{array}{c}\rho \\
\left(\mathrm{Kg} / \mathrm{m}^{3}\right)\end{array}$ & $\begin{array}{c}\mathrm{Cp} \\
(\mathrm{J} / \mathrm{kg} \mathrm{k})\end{array}$ & $\begin{array}{c}\mathrm{k} \\
(\mathrm{W} / \mathrm{m} \mathrm{k})\end{array}$ & $\begin{array}{c}\beta^{*} 10^{5} \\
\left(\mathrm{k}^{-1}\right)\end{array}$ & $\begin{array}{c}\alpha^{*} 10^{5} \\
\left(\mathrm{~m}^{2} / \mathrm{s}\right)\end{array}$ \\
\hline Distilled water & 6.2 & 997.1 & 4179 & 0.613 & 21 \\
\hline \multicolumn{6}{c}{ Nanoparticles } \\
\hline Copper $(\mathrm{Cu})$ & & 8933 & 385 & 401 & 1.67 & 11.7 \\
\hline Zirconium oxide $\left(\mathrm{ZrO}_{2}\right)$ & & 5890 & 278 & 22.7 & & 12.4
\end{tabular}

\section{THE SHADOW SYSTEM FOR THE EVACUATED TUBE SOLAR COLLECTOR}

An electric curtain will shade the solar collector to regulate the solar collector's temperature to improve the performance of the solar collector as well as Increase efficiency. The purpose of the controller is to track the motion of the curtain in case of up or down, mechanical and electrical parts moving the curtain up and down Depending on the required conditions of motion control. This curtain is made of white rubber (Flex) material and is considered one of the best printing materials because it is characterize $\mathrm{d}$ by resistance to tension, pressure and different weather condition. Fig. 4 show the test rig with shadow system.

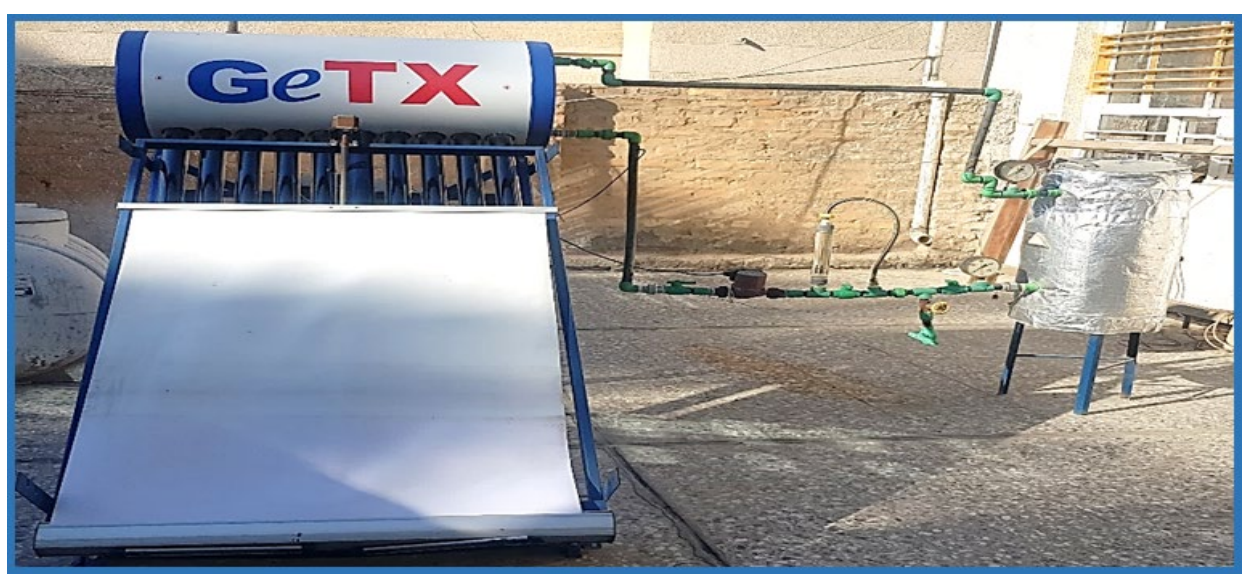

Figure 4-a: the test rig with shadow system

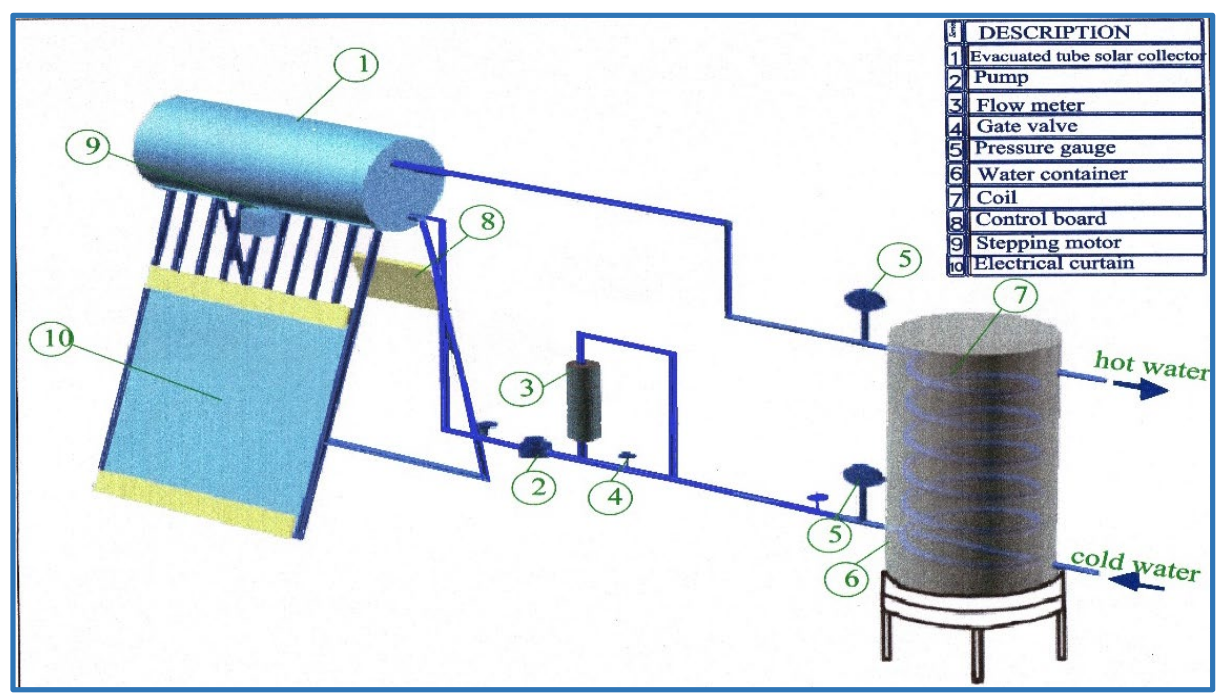

Figure 4-b: show the Schematic diagram of the ETSC with shadow system 


\section{COMPONENTS USED IN SHADE THE SOLAR COLLECTORS}

Here we explain the response to electric curtain control devices. The control system consists of a mechanical and an electrical parts. Where a mechanical part consist main exterior frame with different levels of bases. This frame has the function of installing the electric curtain and installing the stepper motor as well. The electric curtain and the stepper motor are connected by screw rotate in the stepper direction and the second fixed by nut welded on the curtain and the screw end is bearing as shown in Fig .5. Another mechanical part is the insulating curtain with base, the base of the curtain is made of aluminium metal to be lightweight and inside the base is a curtain as shown in Fig.6 .From another hand the electrical part consists of a stepper motor which provides easy control with precise positioning, and pulse signals provide true control. A stepping motor rotates at a fixed angle for each pulse; it is connected to the screw which unlocks the curtain in effect. From another side the stepper is connected to a control system and the purpose of this connection is to move the stepper which will rotate the curtain for shading the solar collector as shown in Fig.7 and a power supply which used to convert voltages from $220 \mathrm{~V}$ to $24 \mathrm{~V}$ and $10 \mathrm{~A}$ for stepper motor board, in addition microcontroller (Arduino), Figu8 Shows an electrical component of the control board.
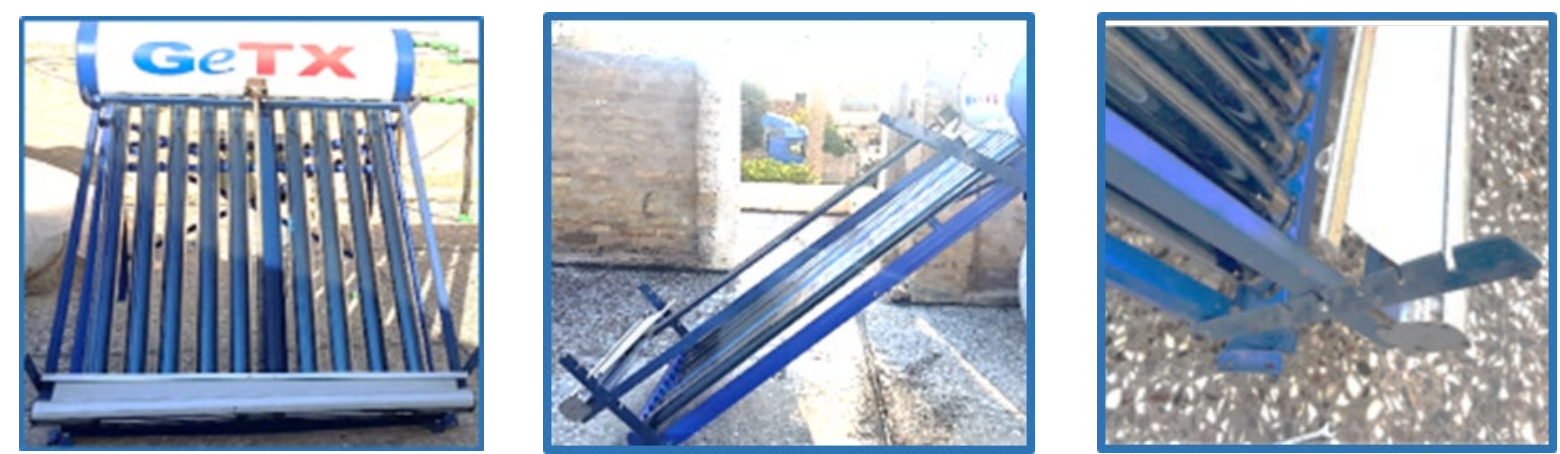

Figure 5: The main exterior frame with different levels of bases

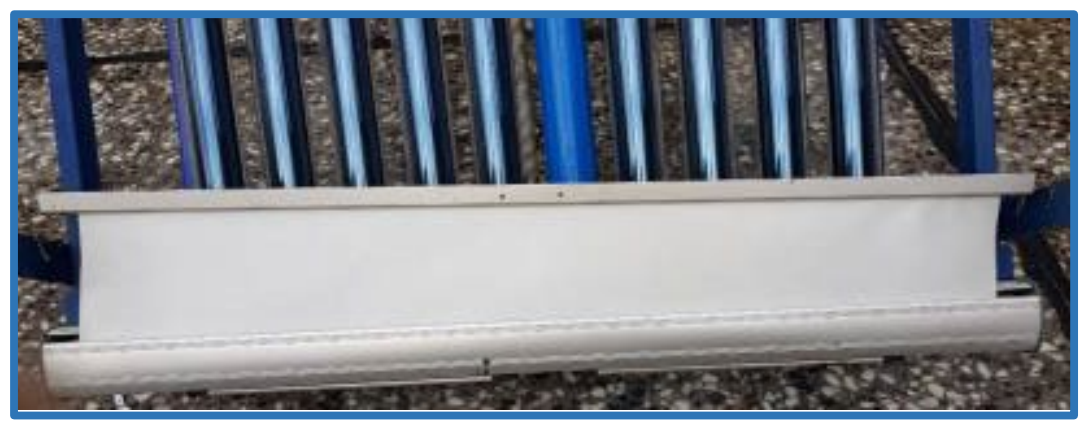

Figure 6: the insulating curtain with bases
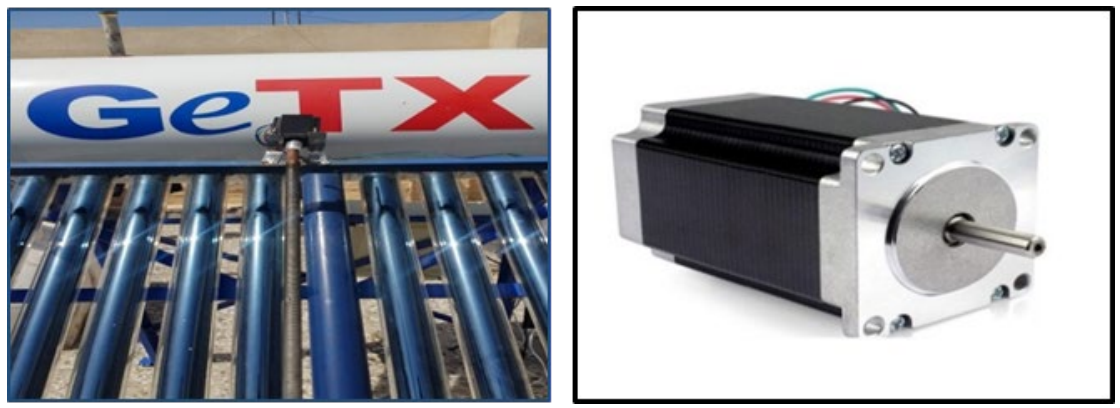

Figure 7: stepper motor (MEMA 23 stepping motor) 


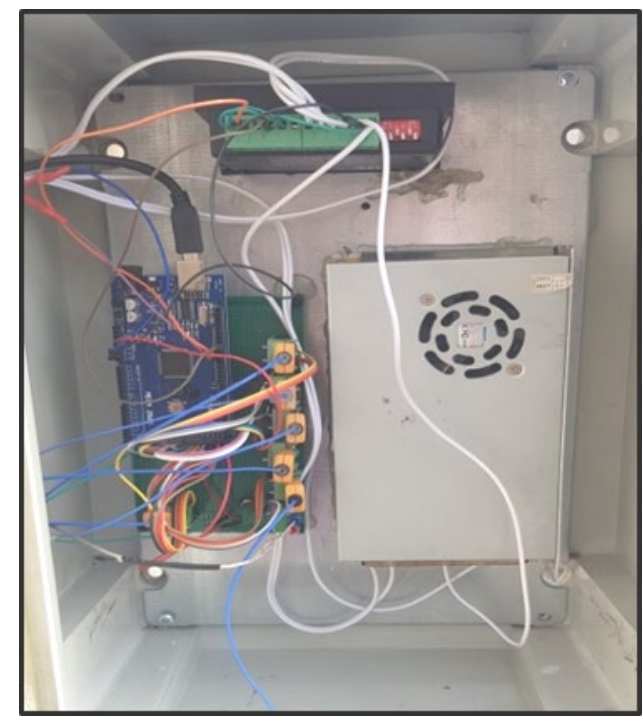

Figure 8: control board

\section{SOFTWARE PROGRAM}

The implementation particle swarm optimization (PSO) embedded in Arduino MEGA for proportional - integral - derivative controller (PID) tuning as a validation for real - time hardware application on the solar collector system, PSO Perform the search technique many times, and get the optimal results as follows; Proportional gain, $\mathrm{Kp}=0.84$, Integral gain and $\mathrm{Ki}=0.21$ Derivative gain, $\mathrm{Kd}=0.43$. The Arduino interface is connected to (PLX - DAQ) which is a Parallax microcontroller data acquisition tool. Microcontrollers attached on any sensor and serial port of a PC can send data directly to Excel, using Microsoft Excel to graph or plot data as it arrives in real time. Note in the previous STEPS when the control system sense that fluid temperature is equal or less than $\left(40^{\circ} \mathrm{C}\right)$, the curtain shading is fully open, especially at night and the beginning of the morning and with the rise of solar radiation will rise the temperature and when it reaches $\left(50^{\circ} \mathrm{C}\right)$ will move the curtain at $(30 \mathrm{~cm})$ and gradually increase, the curtain will move depending on the temperature of the fluid until the overall shading and low temperature will move the curtain down and depends on the movement of the curtain on the value specified in the past during programming, can be programmed motion of the curtain and temperatures according to the choice of the designer and according to the environment surrounding system.

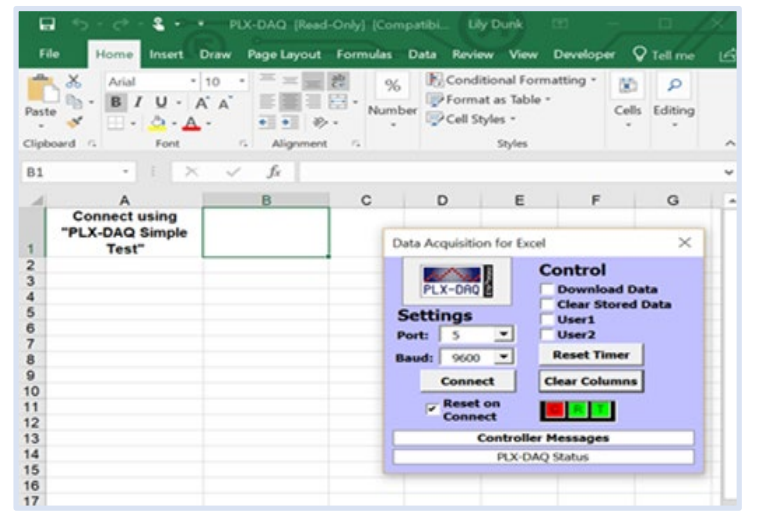

Figure 9: Diagram for soft programmer PLX - DAQ 

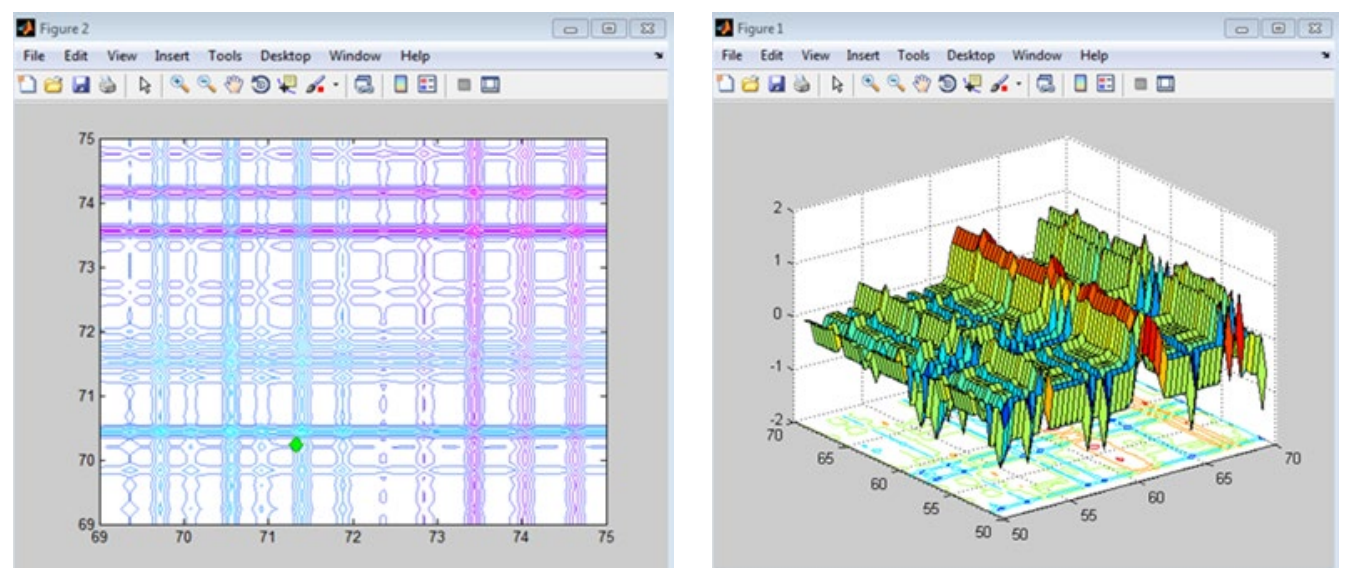

Figure 10: response and surface view of temperature Evacuated tube using PSO controller

\section{Simulation and Mathematical Model using Intelligent Control TechniQues (PSO-PID)}

To show the efficacy of the PSO-based PID controller interface scheme for control the temperature of the evacuated tube solar collector, a Simulink is built in m-file in MATLAB for find minimum temperature for working shadow system in open or close to keep evacuated tube in steady state and close shadow system when temperature become near or equal $70 \mathrm{C}^{\circ}$.

\section{The simulation model of temperature for the evacuated tube solar collector}

Demonstrate the efficacy of proposed methods (PSO - PID) controller design scheme which is optimized using PSO algorithms for evacuated tube solar collector system to find minimum temperature for working shadow system in open or close to keep evacuated tube in steady state and close shadow system when temperature become near or equal $70^{\circ} \mathrm{C}$, using Nano fluids $(\mathrm{Cu}(30 \mathrm{~nm})$ $+\mathrm{DW})$ and $(\mathrm{ZrO} 2(50 \mathrm{~nm})+\mathrm{DW})$ at various concentration by insert a set point of temperature then go to controller PSO- PID and finally go to switch to open or close the shadow system.

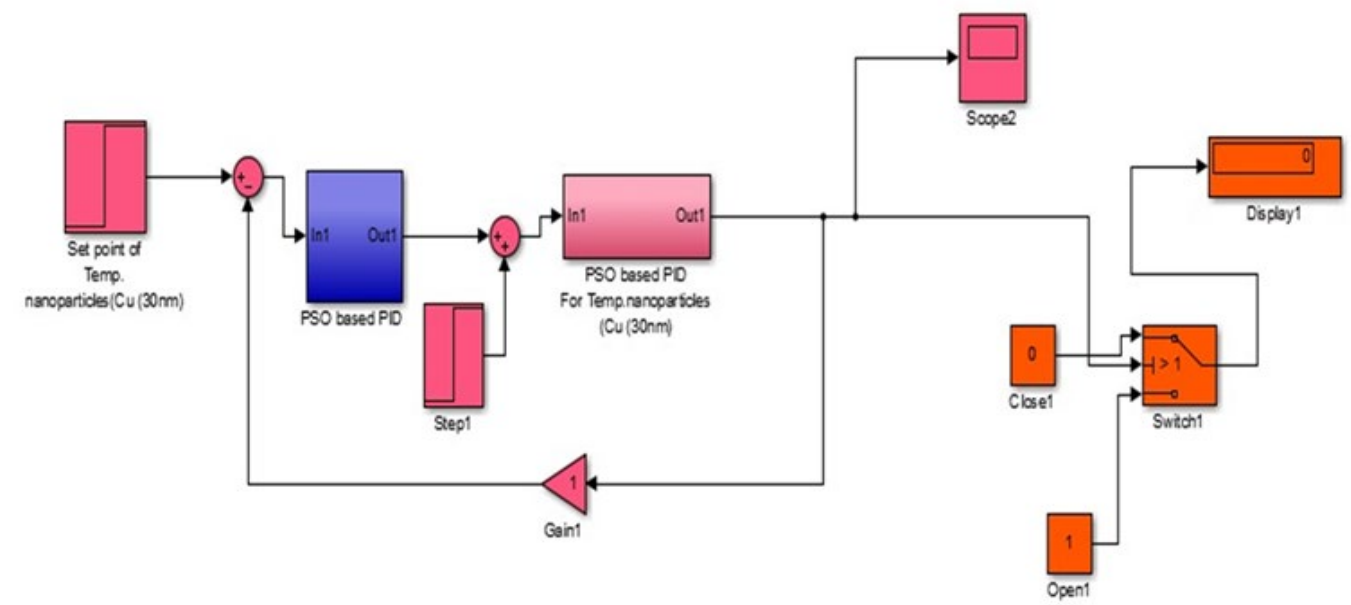

Figure 11: Simulink model and response of evacuated tube system with PSO-PID Controller Using Nano-fluids (Cu (30nm) +DW) 


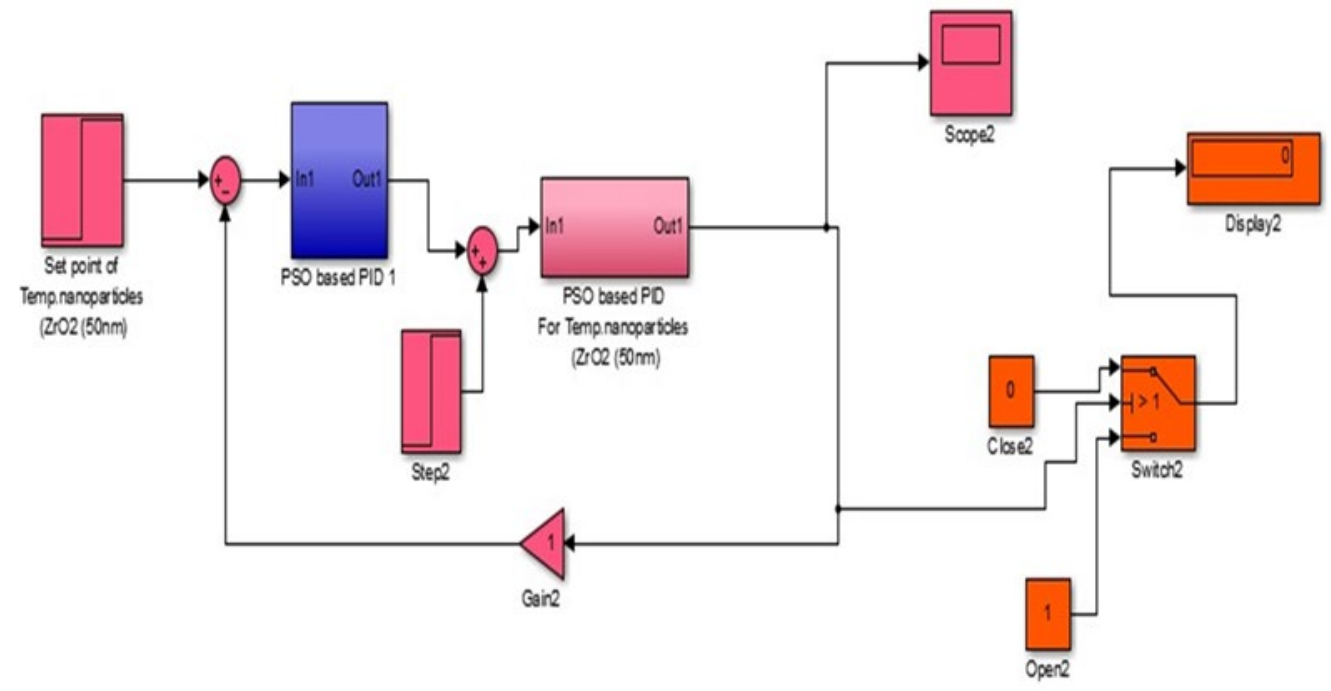

Figure 12: Simulink model of evacuated tube system with PSO-PID Controller Using Nano fluids $(\mathrm{ZrO2}(50 \mathrm{~nm}))$

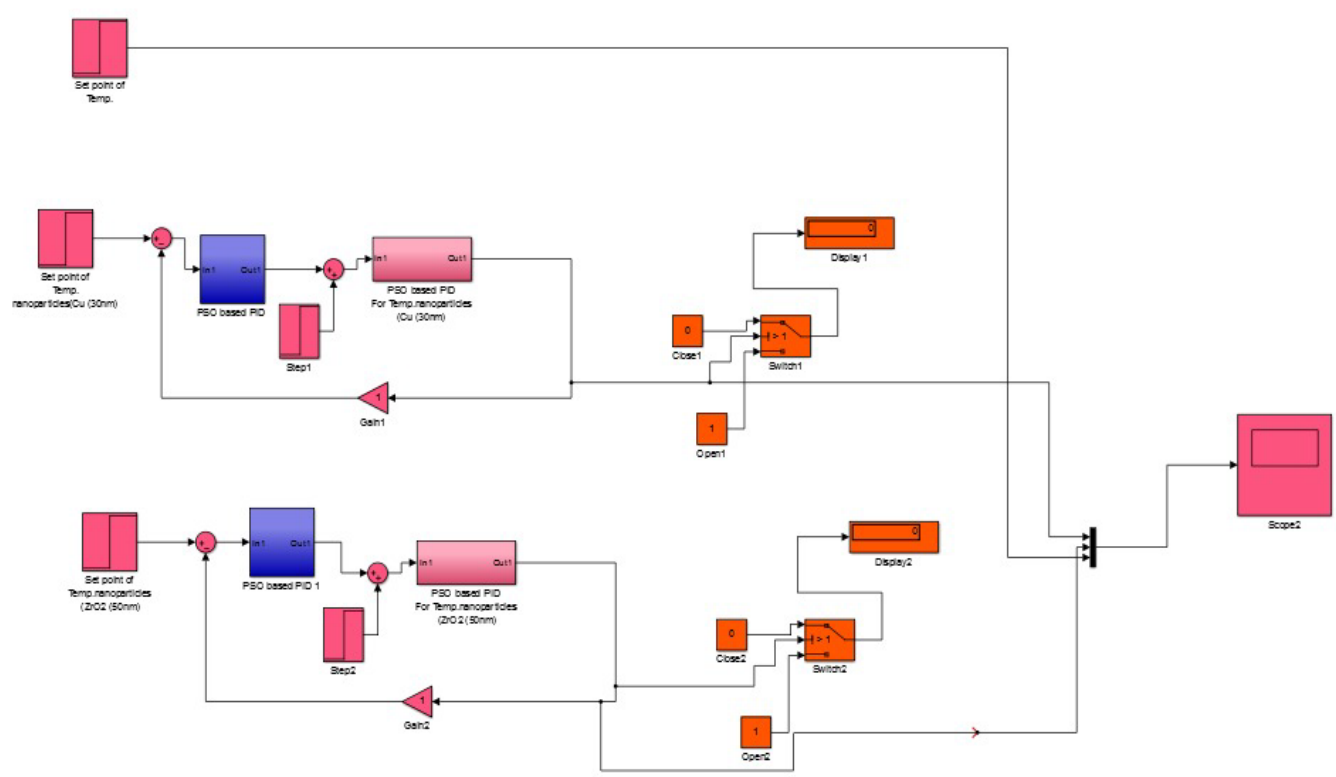

Figure 13: Comparison Simulink model and response of evacuated tube system with (PSO-PID) Controller Using Nano-particles ( $\mathrm{Cu}(30 \mathrm{~nm}))$ and $(\mathrm{ZrO2}(50 \mathrm{~nm})$

\section{Comparison Simulink model and response of evacuated tube system using (PSO-PID) with classical PID controller}

The performance of PSO based PID and classical PID has been compared in terms of overshoot, rise time and settling time. 


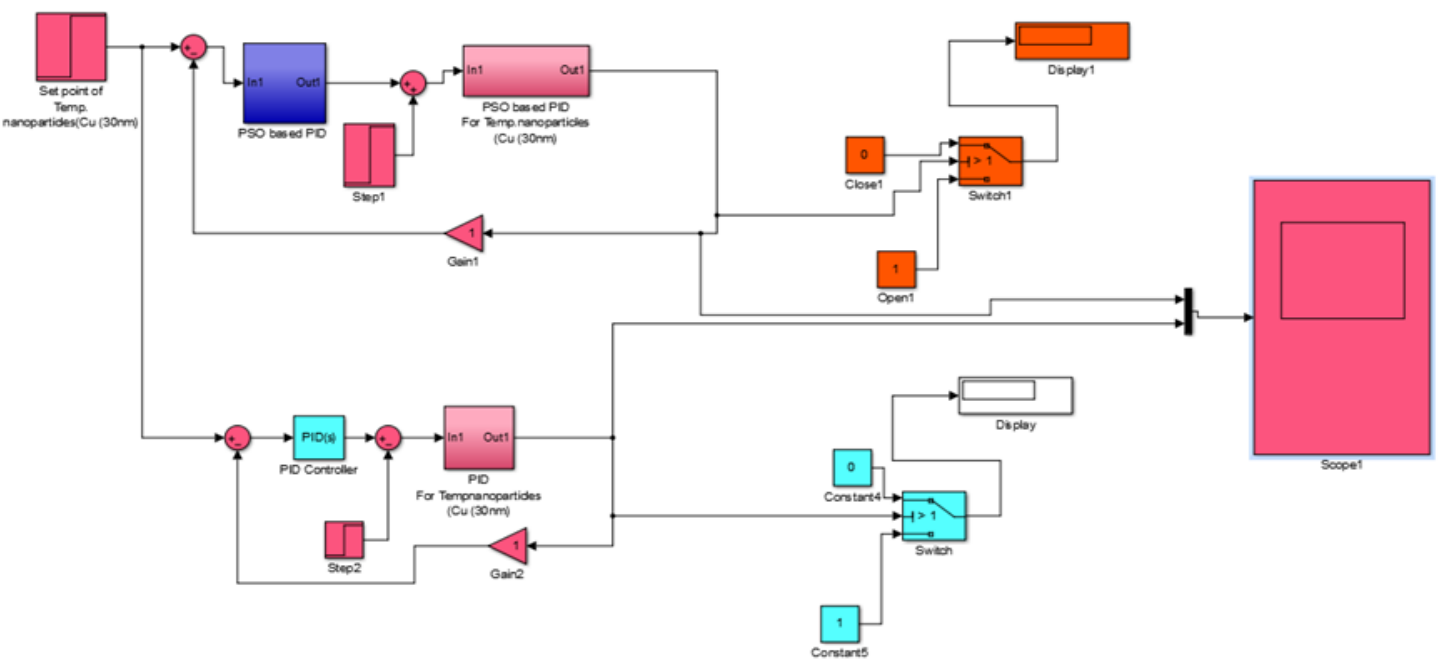

Figure 14: Comparison Simulink model of evacuated tube system using (PSO -PID) controller with classical PID controller when using Nano fluids $(\mathrm{Cu}(30 \mathrm{~nm})+\mathrm{DW})$

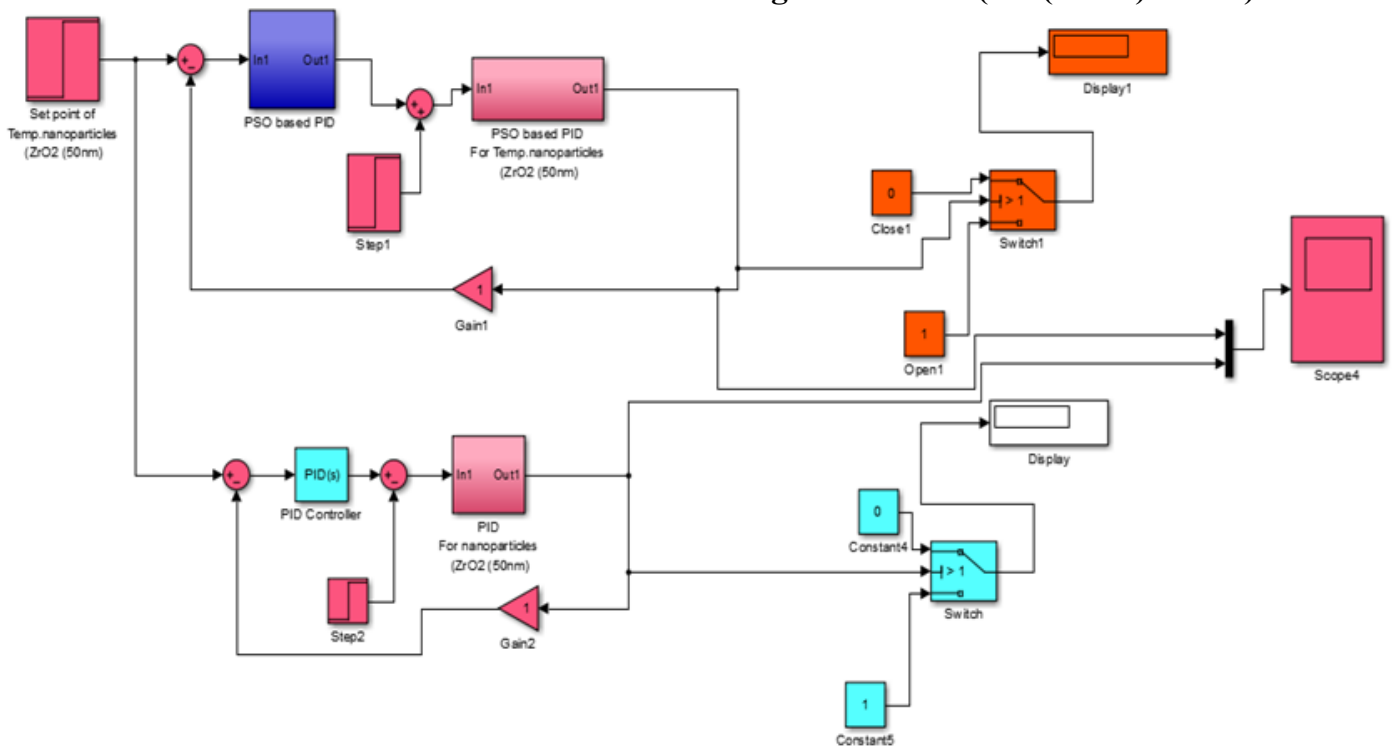

Figure 15: Comparison Simulink model of evacuated tube system using (PSO -PID) controller with classical PID controller when using Nano fluids (ZrO2 (50nm) + DW)

\section{RESULTS}

Figure 16 and Table III shows the temperature increase with time of evacuated tube system, using( PSO based PID ) controller, This result gave a small setting time.
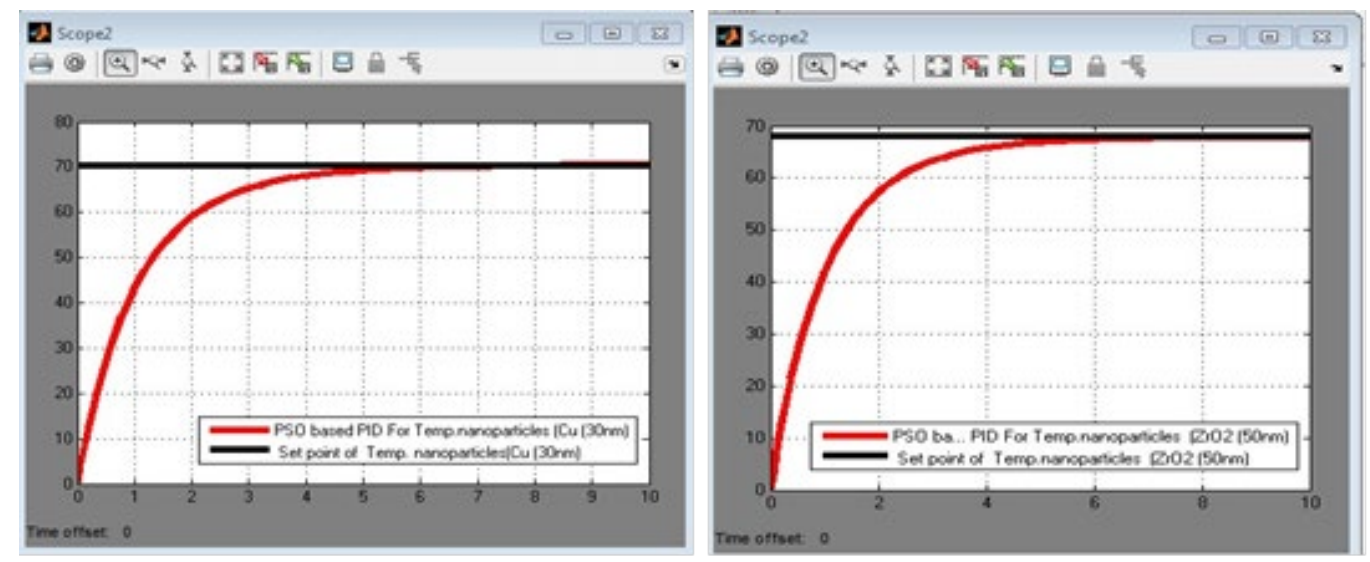

Figure 16: Response comparison simulation of Evacuated tube with PSO -PID controller Using Nano-particles (Cu (30nm)) and (ZrO2 (50nm) 
Table III: Results of (PSO- PID) technique of Evacuated tube solar collectors when using two Types of Nano fluids

\begin{tabular}{ccccc}
\hline Performance parameters & $\begin{array}{c}\text { Rise } \\
\text { Time }\end{array}$ & $\begin{array}{c}\text { Settling } \\
\text { Time }\end{array}$ & $\begin{array}{c}\text { Peak } \\
\text { Value }\end{array}$ & Overshoot \\
\hline $\begin{array}{c}\text { (PSO- PID) using Nano fluids } \\
(\mathrm{Cu}(30 \mathrm{~nm}))\end{array}$ & 4.3 & 5 & 70 & $2.94 \%$ \\
\hline $\begin{array}{c}\text { (PSO-PID) Using Nano fluids } \\
(\mathrm{ZrO} 2(50 \mathrm{~nm})\end{array}$ & 4 & 6 & 68 & $4.61 \%$ \\
\hline Set points & 0 & 0 & 70 & 0
\end{tabular}

Figure 17 and Table IV show comparison results evacuated tube system using intelligent techniques (PSO based PID) with classical PID, observed that( PSO -PID) method has the fastest rise time compared with PID method, (PSO -PID) method achieves steady-state at $\mathrm{t}=6.3 \mathrm{sec}$ Thus PID achieves steady-state at $\mathrm{t}=18 \mathrm{sec}$.

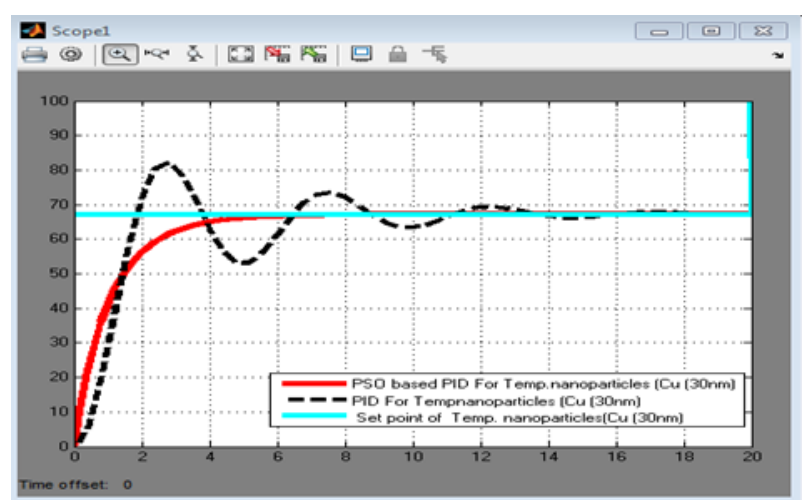

Figure 17: Results of comparison of intelligent technique (PSO-PID) with classical PID using nanofluids $(\mathrm{Cu}(50 \mathrm{~nm})+\mathrm{DW})$

Table IV: Results of comparison of intelligent technique

\begin{tabular}{cccccc}
\hline Performance parameters & $\begin{array}{c}\text { Rise } \\
\text { Time }\end{array}$ & $\begin{array}{c}\text { Settling } \\
\text { Time }\end{array}$ & $\begin{array}{c}\text { Peak } \\
\text { Value }\end{array}$ & Overshoot \\
\hline Controller & 2.1 & 6.3 & 70 & $12.8 \%$ \\
\hline (PSO- PID) & 4 & 18 & 68 & $22.8 \%$ \\
\hline PID & 0 & 0 & 70 & 0
\end{tabular}

Figure 18 and Table $\mathrm{V}$ show show comparison results evacuated tube system using intelligent techniques (PSO based PID) with classical PID ,( PSO -PID ) achieves steady-state at $t=6 \mathrm{sec}$ Thus PID achieves steady-state at $t=17 \mathrm{sec}$, In contrast, the proposed method has much faster and accurate response than of the other classical methods. 


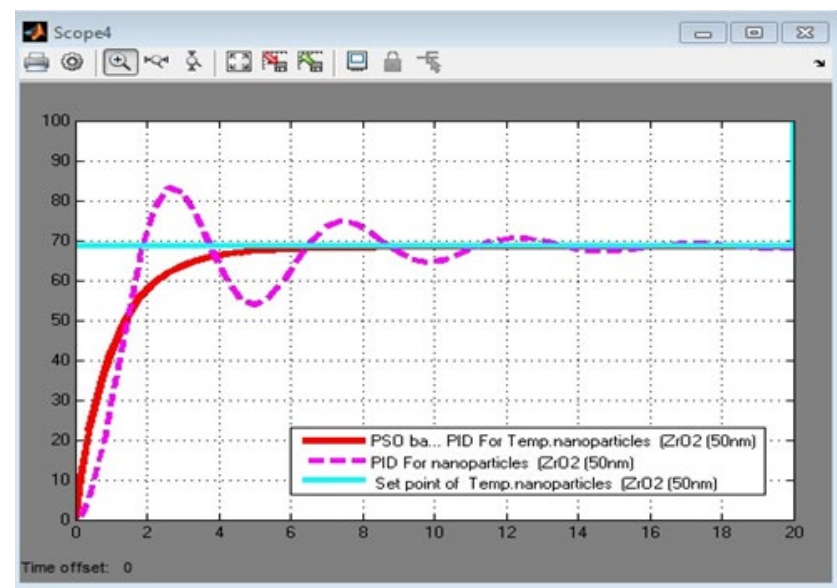

Figure 18: Results of comparison of intelligent technique (PSO-PID) with classical PID using nanofluids (ZrO2(50nm)+DW)

Table V: Results of comparison of intelligent technique

\begin{tabular}{cccccc}
\hline Performance parameters & $\begin{array}{c}\text { Rise } \\
\text { Time }\end{array}$ & $\begin{array}{c}\text { Settling } \\
\text { Time }\end{array}$ & $\begin{array}{c}\text { Peak } \\
\text { Value }\end{array}$ & Overshoot \\
\hline Controller & 4 & 6 & 68 & $1.47 \%$ \\
\hline PSO-PID & 2.7 & 17 & 83 & $20.2 \%$ \\
\hline PID & 0 & 0 & 70 & 0
\end{tabular}

Figure 19 At the beginning of the shading process, a relationship was drawn between the temperature and the distance of the electric curtain movement other than the high shading of the solar collector and starting at $\left(40^{\circ} \mathrm{C}\right)$, all nanofluids are stable and the curtain is fully open and at high temperatures will move the curtain for different distances and note from the plan that the solar collector's temperature can be reduced as best as possible when adding the nanofluids $(\mathrm{Cu}+\mathrm{DW})$ with a height of $(35 \mathrm{~cm})$. Fig.20 show the relationship between the temperature and the different distances of the movement of the electric curtain in addition to the height when adding another type of nanofluids such as $\left(\mathrm{ZrO}_{2}+\mathrm{DW}\right)$ after this change when adding the other fluid will decrease temperatures and helps to cool solar collector especially at the curtain height of $(35 \mathrm{~cm})$. Fig. 21 and Fig. 22 Shows the relationship between the temperature with various time in march month, as well as the height of the curtain of the solar collector using distilled water and two types of nanofluids $\left(\mathrm{Cu}+\mathrm{ZrO}_{2}-\mathrm{Dw}\right)$.Fig. 23 and Fig. 24 also Shows the relationship between the temperature with variou time in april month, as well as the height of the curtain of the solar collector using pure water and two types of nanofluids( $\left.\mathrm{Cu}+\mathrm{ZrO}_{2}-\mathrm{Dw}\right)$, we always notice the curtain height on the solar collector $(35 \mathrm{~cm})$ is better than other levels in addition to the use of the first type $(\mathrm{Cu}+\mathrm{Dw})$ is best because it contains metal materials.

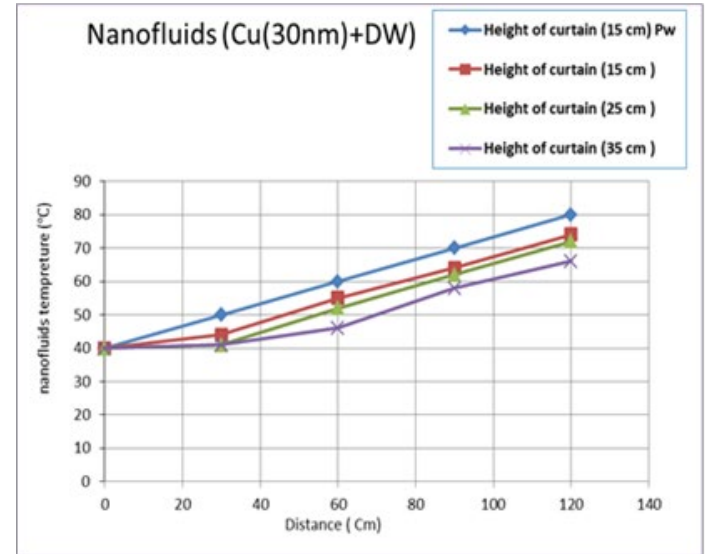

Figure 19: various of outlet temperatures for solar collector using nanofluid (cu(30nm)+DW) at different curtain hight and distance

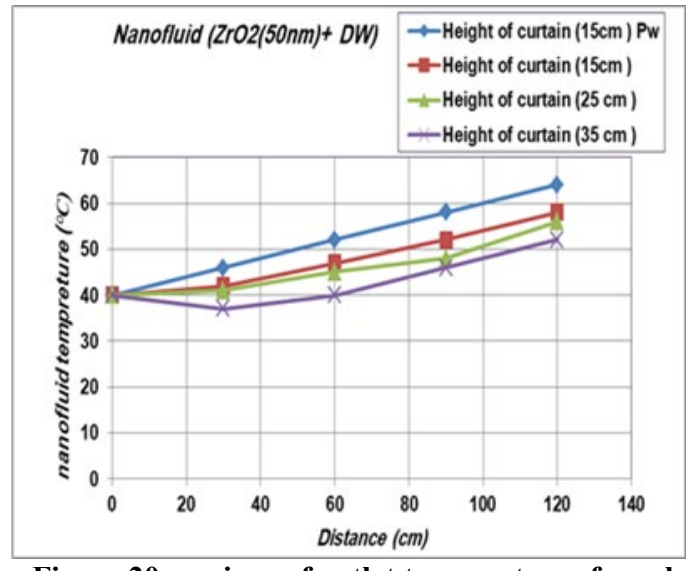

Figure 20: various of outlet temperatures for solar collector using nanofluid $\left(\mathrm{ZrO}_{2}(50 \mathrm{~nm})+\mathrm{DW}\right)$ at different curtain hight and distance 


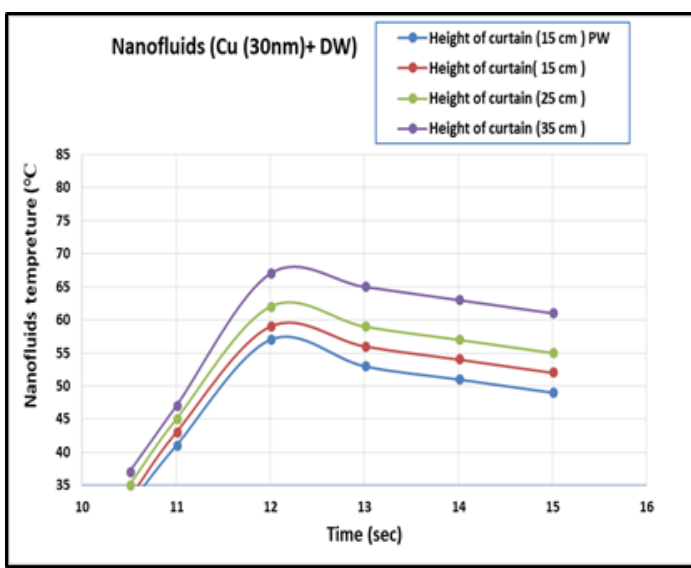

Figure 21: variuos of outlet temperature of solar collector for nanofluid $(\mathrm{Cu}+\mathrm{DW})$ at different time and curtain height

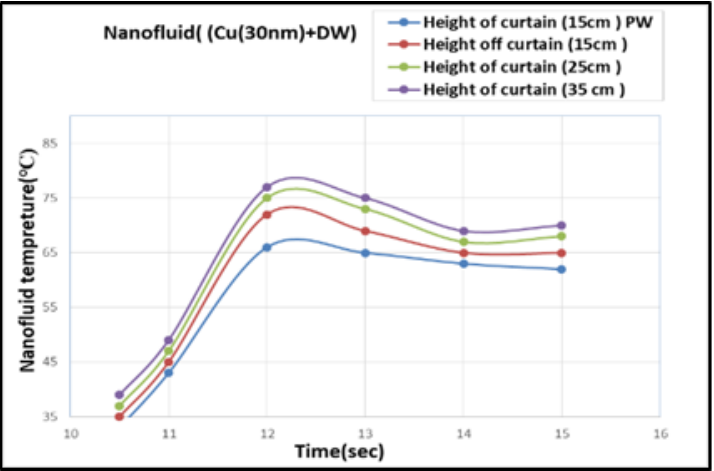

Figure 23: various of outlet temperature of solar collector for nanofluid $(\mathrm{Cu}+\mathrm{DW})$ at different time and curtain height

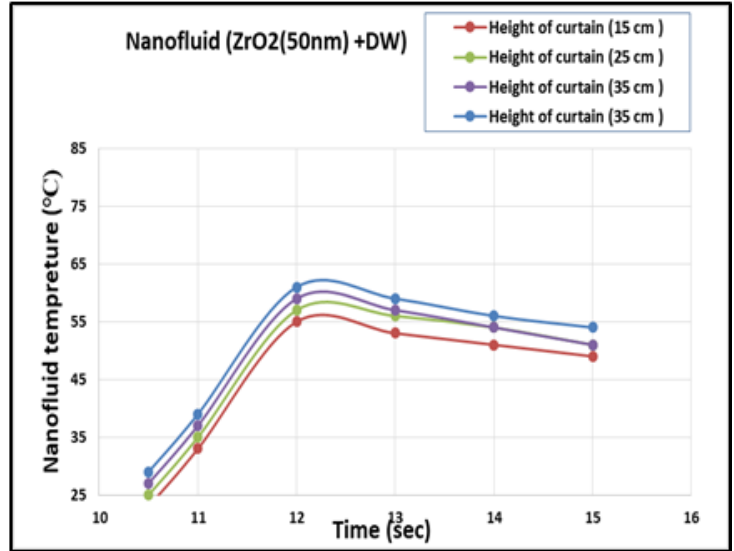

Figure 22: various of outlet temperature of solar collector for Nano fluid ( $\mathrm{ZrO2}+\mathrm{DW})$ at different time and curtain height

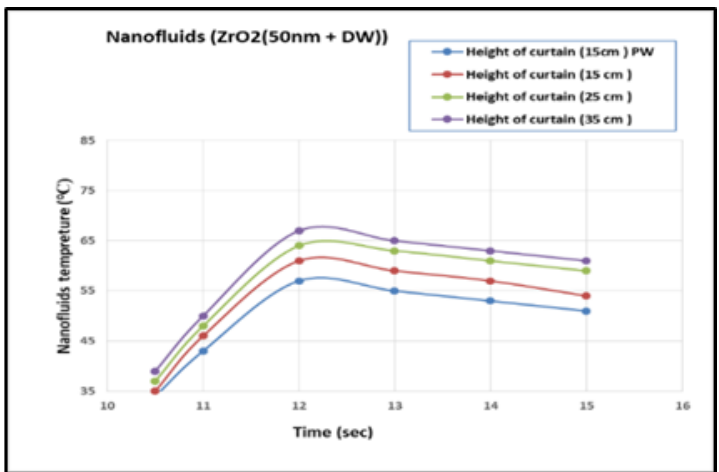

Figure 24: various of outlet temperature of solar collector for nanofluid $(\mathrm{ZrO2}+\mathrm{DW})$ at different time and curtain height

\section{CONCLUSION}

1. The electric curtain has the task of controlling Nano fluids temperature and increasing ETSC efficiency.

2. Apply (PSO - PID) method for simulation the ETSC parameter and the performance of those parameters was assessed.

3. PSO - PID controller Is a great choice for achieving the desirable accuracy and efficiency of stepping motor control.

4. The outcome of simulation indicates that the proposed method has a much faster and more reliable response than the other classical methods' response.

5. The embedded PSO-PID provides better performance compared with classical PID controller.

6. PSO algorithms was better than other methods in dealing with the mistake with the least time.

\section{References}

[1] H.A. Kazem, J.H. Yousif. Comparison of prediction methods of photovoltaic power system production using a measured dataset, Energy Convers. Manag., $148 \quad$ (2017) $1070 \quad-1081$. https://doi.org/10.1016/j.enconman.2017.06.058

[2] M.A. Sabiha, R. Saidur, S. Mekhilef, An experimental study on Evacuated tube solar collector using Nano fluids, Trans. Sci. Technol., 2 (2015) 42-49.

[3] R. Kumar, M. A. Rosen, Integrated collector - storage solar water heater with extended storage unit, Appl. Therm. Eng., 31 (2011) 348 - 354. https://doi.org/10.1016/j.applthermaleng.2010.09.021 
[4] S. A. Kalogirou, S.Karellas, K.Braimakis , C. Stanciu , V.Badescu, Exergy analysis of solar thermal collectors and processes , Prog. Energy Combust. Sci., 56 (2016) 106-137. https://doi.org/10.1016/j.pecs.2016.05.002

[5] M.A. Sabiha, R. Saidur, S. Mekhilef, O. Mahian, Progress and latest developments of evacuated tube solar collectors, Renew. Sustain. Energy Rev., 51 (2015) 1038-1054. https://doi.org/10.1016/j.rser.2015.07.016

[6] M.A. Sharafeldin, G. Grof, Evacuated tube solar collector performance using $\mathrm{CeO}_{2} / \mathrm{water}$ Nano fluid, J. Clean. Prod., 185 (2018) 347-356. https://doi.org/10.1016/j.jclepro.2018.03.054

[7] P. Biswas, R. Maiti, A. Kolay, K. Das Sharma and G. Sarkar, PSO Based PID Controller Design for Twin Rotor MIMO System, Proceedings of The 2014 International Conference on Control, Instrumentation, Energy and Communication (CIEC), Calcutta, India, 2014, 56-60. https://doi.org/10.1109/CIEC.2014.6959049

[8] R. Hassan, B. Cohanim, A comparison of particle swarm optimization and the genetic algorithm, 46th AIAA, structure dynamic and material conference, Austin, Texas, 2005, 1-13. https://doi.org/10.2514/6.2005-1897

[9] D.P. Kamble, P.S. Gadhave, M.A. Anwar, Enhancement of Thermal Performance of Heat Pipe Using Hybrid Nano fluid, Int. J. Eng. Trends Technol., 17 (2014) 425- 428.

[10] A. K. Tiwari, P. Ghosh, J. Sarkar, Solar Water Heating Using Nano fluids -A Comprehensive Overview and Environmental Impact Analysis, Int. J. Emerg. Technol. Adv. Eng., 3 (2013) 221 - 224.

[11] H. Aygun, H. Demire, Comparison of PSO-PID, FLC and PID in a Circulating Fluidized Bed Boiler, 7th International Conference on Electrical and Electronics Engineering- ELECO, Bursa, Turkey, 1- 4 December 2011.

[12] I. Tabet; K. Touafek; N. Bellel; N. Bouarroudj; A. Khelifa; M. Adouane, Optimization of angle of inclination of the hybrid photovoltaic-thermal solar collector using particle swarm optimization algorithm, J. Renew. Sustain. Energy, 6 (2014) 053116. https://doi.org/10.1063/1.4896956

[13] Kaveh, A. Advances in Metaheuristic Algorithms for Optimal Design of Structures, Springer International Publishing, 2017.

[14] M.A.Mohandes, Modeling global solar radiation using Particle Swarm 0ptimization (PSO), Sol. Energy, 86 (2012) 3137-3145. https://doi.org/10.1016/j.solener.2012.08.005

[15] V. Siddhartha, N. Sharma, G. Varun, a particle swarm optimization algorithm for optimization of thermal performance of a smooth flat plate solar air heater, Energy, 38 (2012) $406 \quad-413$. https://doi.org/10.1016/j.energy.2011.11.026

[16] P. Biswas, R. Maiti, A. Kolay, K.D. Sharma, PSO Based PID Controller Design for Twin Rotor MIMO System, Proceedings of The 2014 International Conference on Control, Instrumentation, Energy and Communication (CIEC), Calcutta, India, 2014, 56-60. https://doi.org/10.1109/CIEC.2014.6959049

[17] H. J. Jawad, particle swarm optimization based optimum PID controller for governor system of synchronous generation, AL- Qadisiya J. Eng. Sci., 6 (2013) 315-331. 